\title{
MicroRNA deregulation and pathway alterations in nasopharyngeal carcinoma
}

\author{
H-C Chen', G-H Chen', Y-H Chen', W-L Liao', C-Y Liu', K-P Chang', Y-S Chang' and S-J Chen*,I \\ 'Genomic Core Laboratory, Molecular Medicine Research Center, Chang Gung University, Taiwan, Republic of China; ${ }^{2}$ Department of Otolaryngology, \\ Chang Gung Memorial Hospital at Lin-Kou, Taoyuan, Taiwan, Republic of China
}

MicroRNAs (miRNAs) are a family of small non-coding RNA molecules of about 20-23 nucleotides in length, which negatively regulate protein-coding genes at post-transcriptional level. Using a stem-loop real-time-PCR method, we quantified the expression levels of 270 human miRNAs in 13 nasopharyngeal carcinoma (NPC) samples and 9 adjacent normal tissues, and identified 35 miRNAs whose expression levels were significantly altered in NPC samples. Several known oncogenic miRNAs, including miR-17-92 cluster and miR-155, are among the miRNAs upregulated in NPC. Tumour suppressive miRNAs, including miR-34 family, miR-143, and miR-145, are significantly downregulated in NPC. To explore the roles of these dysregulated miRNAs in the pathogenesis of NPC, a computational analysis was performed to predict the pathways collectively targeted by the 22 significantly downregulated miRNAs. Several biological pathways that are well characterised in cancer are significantly targeted by the downregulated miRNAs. These pathways include TGF-Wnt pathways, GI-S cell cycle progression, VEGF signalling pathway, apoptosis and survival pathways, and IP3 signalling pathways. Expression levels of several predicted target genes in GI-S progression and VEGF signalling pathways were elevated in NPC tissues and showed inverse correlation with the down-modulated miRNAs. These results indicate that these downregulated miRNAs coordinately regulate several oncogenic pathways in NPC. British Journal of Cancer (2009) I 00, 1002-1011. doi:I0.1038/sj.bjc.6604948 www.bjcancer.com (C) 2009 Cancer Research UK

Keywords: microRNA; target; pathway; nasopharyngeal carcinoma

MicroRNAs (miRNAs) are short non-coding RNA molecules involved in post-transcriptional gene regulation (Ambros, 2004; Bartel, 2004). In animals, miRNAs control the expression of target genes by inhibiting translation or degradating target mRNAs through binding to their $3^{\prime}$ UTR (Bartel, 2004). MicroRNAs have been found to regulate genes involved in diverse biological functions, including development, differentiation, proliferation, and apoptosis (Ambros, 2004; Croce and Calin, 2005; Bushati and Cohen, 2007).

Cumulative evidence suggests that miRNAs have major functions in the pathogenesis of tumour. Approximately $50 \%$ of miRNAs are localised in cancer-associated genome regions (Calin et al, 2004; Sevignani et al, 2007). Biological characterisation also identified several miRNAs function as tumour suppressors or oncogenes (Chen, 2005; Croce, 2008). Large scale profiling revealed a global alteration of miRNA expression patterns in human cancers (Lu et al, 2005; Murakami et al, 2006; Kida and Han, 2008). Recently, distinct miRNA expression signatures have been proposed as diagnostic and prognostic markers for various types of human cancer (Yanaihara et al, 2006; Schetter et al, 2008; Yu et al, 2008).

*Correspondence: Dr S-J Chen, Genomic Core Laboratory, Molecular Medicine Research Center, Chang Gung University, 259 Wen-Hwa Ist Road, Kwei-Shan, Taoyuan 333, Taiwan, Republic of China;

E-mail: sjchen@mail.cgu.edu.tw

Received 14 October 2008; revised 27 January 2009; accepted 27 January 2009
Although the biological effects of many miRNAs have been characterised individually (Cimmino et al, 2005; Raver-Shapira et al, 2007; Asangani et al, 2008), the impact of multiple miRNA dysregulation on cellular functions and their roles in tumour progression remain largely unknown. Proteomic and microarray data reveal that although each miRNA may regulate up to hundreds of genes, their effect on individual gene is moderate at best (Lim et al, 2005; Baek et al, 2008; Selbach et al, 2008). Recent studies suggest that multiple miRNAs may work in concert to regulate related targets in a common pathway (Cloonan et al, 2008; Liu et al, 2008). Therefore, pathway analysis, rather than individual target gene characterisation, may provide a better solution to evaluate the biological consequences of global miRNA dysregulation.

To link the miRNA profiling data with biological functions, Gusev et al (2007) has developed a strategy, which calculates the functions and pathways collectively regulated by the coexpressed miRNA on the basis of computationally predicted targets. As all target prediction algorithms generate certain fraction of false positives, these false positives may significantly reduce the data reliability when targets predicted for multiple miRNAs were combined to calculate the functional pathways. Recent microarray and proteomic data have provided valuable insights on target prediction (Grimson et al, 2007). With these refinements implemented in miRNA target prediction, the results of pathway enrichment analysis on the basis of the coregulated targets should provide a good insight into the functional role of dysregulated miRNAs. 
In this study, we used both experimental and computational approaches to assess the functional impact of miRNA dysregulation in nasopharyngeal carcinoma (NPC). Differentially expressed miRNAs were identified by profiling 270 human miRNAs in clinical samples. Target prediction followed by pathway enrichment analysis was conducted to identify the functional pathways specifically regulated by the down-modulated miRNAs. Two modifications were introduced to increase the confidence for target prediction and enhance the specificity for pathway analysis. The identified specific pathways were validated by the expression data and in good agreement with earlier reported pathogenesis in NPC.

\section{MATERIALS AND METHODS}

\section{Tissue RNA preparation}

Samples of NPC tissue and adjacent normal nasopharynx tissue were obtained from patients undergoing surgery and were frozen immediately after surgical resection. Collection and distribution of tissue specimens were performed in accordance with the Institutional Regulation Board of Chang Gung Memorial Hospital, Taiwan. Total RNA was prepared using TRIzol reagent (InVitrogen, Carlsbad, CA, USA) according to the manufacturer's protocol. The concentration of RNA was quantified using a NanoDrop Spectrophotometer. The RNA integrity was evaluated by Agilent 2100 BioAnalyzer (Agilent Technologies, Palo Alto, CA, USA). RNAs with an RNA integrity number (RIN) $>7.5$ were used for miRNA and mRNA quantifications.

\section{Reverse transcription (RT)}

For miRNA quantification, a pulsed RT reaction, as described by Chen et al (2005), was performed to convert all miRNAs into corresponding cDNAs in one $\mathrm{RT}$ reaction. Briefly, $10-\mu \mathrm{l}$ reaction mixture containing miRNA-specific stem-loop RT primers (final $2 \mathrm{nM}$ each), $500 \mu \mathrm{M}$ dNTP, $0.5 \mu$ l Superscript III (InVitrogen), and $1 \mu \mathrm{g}$ total RNA were used for the RT reaction. The pulsed RT reaction was performed as follows: $16^{\circ} \mathrm{C}$ for $30 \mathrm{~min}$, followed by 50 cycles at $20^{\circ} \mathrm{C}$ for $30 \mathrm{~s}, 42^{\circ} \mathrm{C}$ for $30 \mathrm{~s}$, and $50^{\circ} \mathrm{C}$ for $1 \mathrm{~s}$. To quantify mRNA transcripts, $1 \mu \mathrm{g}$ of total RNA was converted into cDNA using a random hexamer as primer in a $10-\mu \mathrm{l}$ reaction with the following conditions: $16^{\circ} \mathrm{C}$ for $30 \mathrm{~min}$, followed by $42^{\circ} \mathrm{C}$ for $90 \mathrm{~min}$. Reverse transcription products were diluted 20 -folds before using for miRNA and mRNA Q-PCR reactions.

\section{Quantitative RT-(RT-qPCR) PCR}

For miRNA quantification, $1 \mu \mathrm{l}$ of diluted RT product was used as template for a $10 \mu \mathrm{l} \mathrm{PCR}$. Briefly, $1 \times$ SYBR Master Mix (Applied Biosystem, Foster City, CA, USA), $200 \mathrm{~nm}$ miRNA-specific forward primer, and $200 \mathrm{nM}$ universal reverse primer were used for each PCR reaction. The condition for Q-PCR is $95^{\circ} \mathrm{C}$ for $10 \mathrm{~min}$, followed by 40 cycles of $95^{\circ} \mathrm{C}$ for $15 \mathrm{~s}$ and $63^{\circ} \mathrm{C}$ for $32 \mathrm{~s}$, and a dissociation stage. Endpoint reaction products were analysed on a $10 \%$ polyacrylamide gel stained with ethidium bromide to discriminate the correct amplification product $(57-60 \mathrm{bp})$ and the potential primer dimmers ( $<44 \mathrm{bp})$. For mRNA quantification, the following PCR conditions were used: $95^{\circ} \mathrm{C}$ for $10 \mathrm{~min}$, followed by 45 cycles of $95^{\circ} \mathrm{C}$ for $15 \mathrm{~s}$ and $60^{\circ} \mathrm{C}$ for $1 \mathrm{~min}$, and a dissociation stage. All Q-PCR reactions were performed on an ABI Prism 7500 Fast Real-Time PCR system (Foster City, CA, USA).

\section{Data analysis}

The threshold cycle $\left(C_{\mathrm{t}}\right)$ is defined as the cycle number at which the change of fluorescence intensity crosses the threshold of 0.2 . Of the 270 miRNAs evaluated, 47 showed the expression level below the detection limit $\left(C_{\mathrm{t}}>35\right)$ in more than $70 \%$ of samples, and were excluded from the analysis. For the remaining 223 miRNAs, raw $C_{\mathrm{t}}$ data were converted to $39-C_{\mathrm{t}}$ normalised by global median normalisation before further analysis. For mRNA expression, the average $C_{\mathrm{t}}$ of $\beta$-2-microglobulin, actin, and GAPDH was subtracted from the raw $C_{\mathrm{t}}$ value to obtain $\delta-C_{\mathrm{t}}\left(\mathrm{d} C_{\mathrm{t}}\right)$. The experimentally normalised $\mathrm{d} C_{\mathrm{t}}$ values were converted to $39-C_{\mathrm{t}}$ used to analyse the expression level of human mRNA transcripts.

Statistical analyses used for miRNA and mRNA expression data including two-sample $t$-tests (two-tailed), paired-sample $t$-test (two-tailed), Mann-Whitney test, principle component analysis, Pearson's correlation analysis, and hierarchical clustering were performed with Partek Genomics Suite (version 6.3, St Louis, MO, USA). Pathway enrichment analysis was performed using the MetaCore database (GeneGO, St Joseph, MI, USA). P-values for pathway enrichment analysis were calculated using the formula for hypergeometric distribution and reflects the probability for a pathway to arise by chance.

\section{RESULTS}

\section{Identification of differentially expressed miRNA in human} NPC

The roles of miRNA dysregulation in the pathogenesis of NPC have not been well explored. To identify miRNAs differentially expressed in NPC, we analysed the expression levels of 270 human miRNAs in 13 NPC and 9 normal nasopharyngeal tissues. These samples include seven pairs of NPC and their adjacent normal tissues from same patients. MicroRNA profiling was performed using a stem-loop RT-qPCR method as described by Chen et al (2005). The stem-loop RT-qPCR assay has been proven to offer high sensitivity and specificity for the quantification of mature miRNAs. The expression data of 47 miRNAs were eliminated from further analysis because of their low abundance in all samples tested $\left(C_{\mathrm{t}}>35\right)$. Expression levels of the remaining 223 miRNAs were expressed as $39-C_{\mathrm{t}}$ after global median normalisation.

Unsupervised hierarchical clustering analysis using expression levels of all 223 detectable miRNAs in the seven paired normalNPC tissues generated a tree with normal and NPC samples clearly separated into two groups (Figure 1A). To identify differentially expressed miRNAs in normal and NPC tissues, two statistical tests (two-sample $t$-test and Mann-Whitney rank test) were performed. Expression of 35 miRNAs was significantly altered in NPC samples (fold change: $\geqslant 3$; false discovery rate: $<0.05$; Figure $1 \mathrm{~B}$ ). Among them, 11 miRNAs, including miR-196b, miR-138, miR-155, miR-142-3p, and miR-18a, were significantly upmodulated and 24 miRNAs, including miR-204, miR-449a, miR-34c-3p, miR-143, and miR-145, were down-modulated in NPC samples. Complete list of differentially expressed miRNAs and their chromosome location are shown in Table 1. Similar results were obtained when the miRNA expression levels were normalised using the geometric mean of two reference miRNAs, miR-103 and miR-191, as suggested by Peltier and Latham (2008; Supplementary Figure S1 and Supplementary Table S1).

To test whether the differentially expressed miRNAs selected from paired samples show similar trend of alteration in unpaired samples, we included two additional normal and six additional NPC samples for the principal component analysis (PCA). As shown in Figure 1C, the PCA analysis showed a complete segregation between the 9 normal and 13 NPC samples. Unsupervised hierarchical clustering with the 35 altered miRNAs showed a clear separation between NPC and normal samples. Expression levels of four most significantly upregulated miRNAs and four most significantly down-modulated miRNAs in NPC tissues were shown in Figure 2A and B. The global alteration in 
A

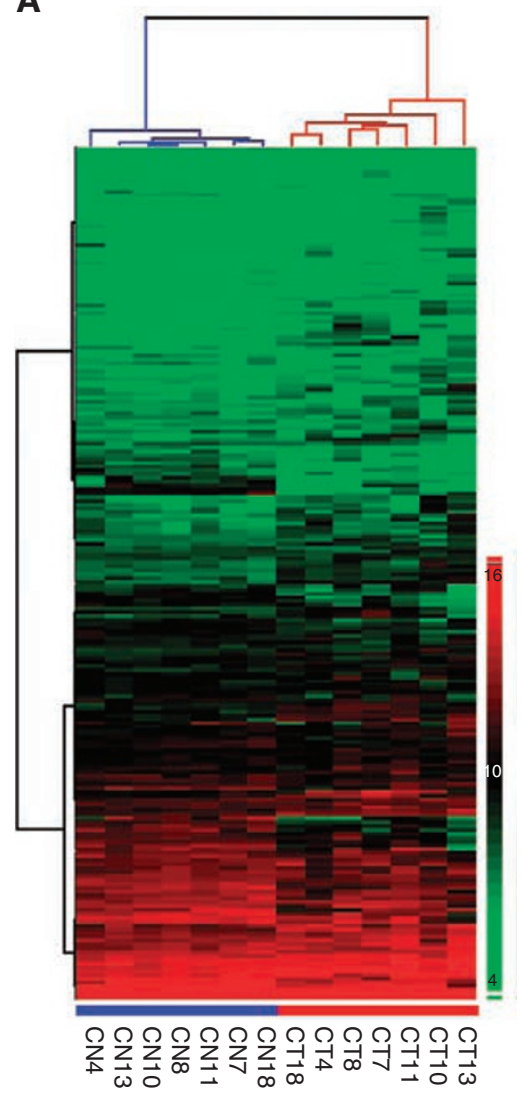

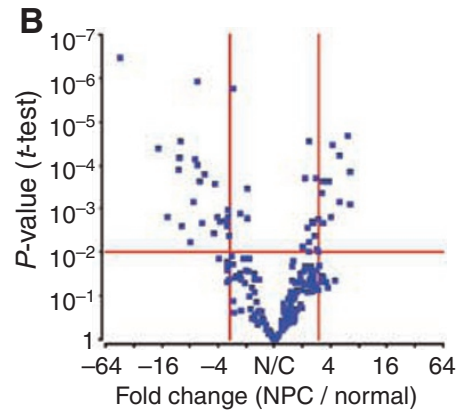

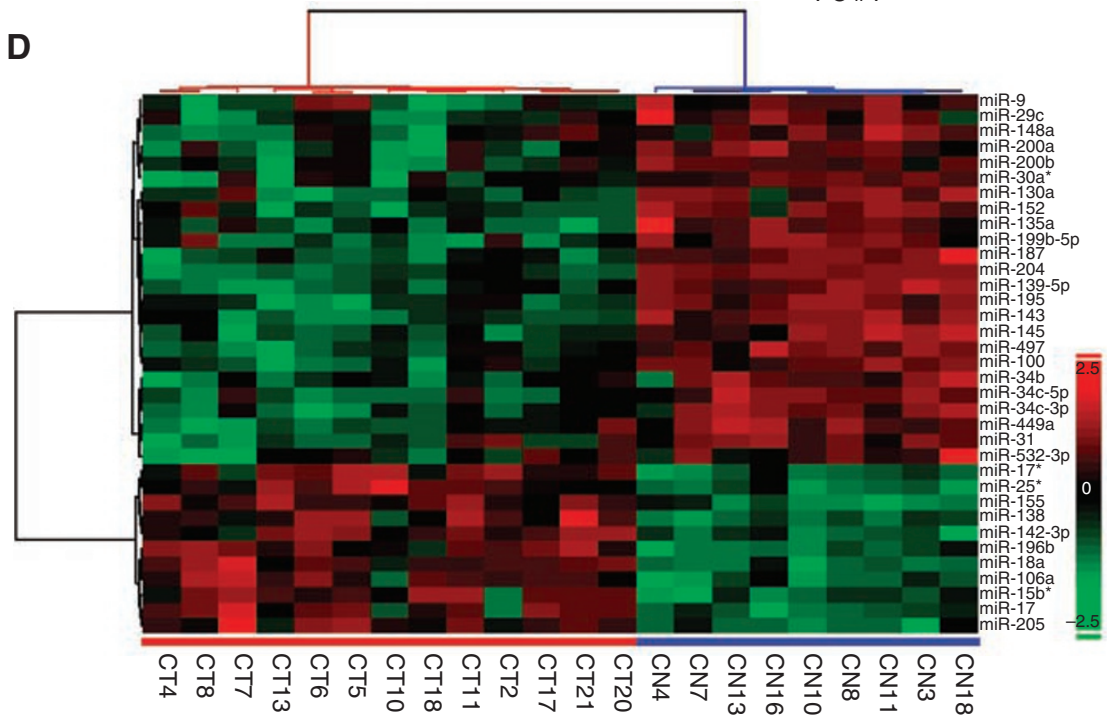

Figure I MicroRNA (miRNA) expression patterns distinguish normal from NPC tissues. (A) Unsupervised hierarchical clustering of 223 miRNAs in seven normal (blue)-NPC (red) paired tissues. The hierarchical clustering was performed using squared Euclidean as distance measure and Ward's method for linkage analysis. MicroRNA levels were expressed as $39-C_{t}$ after global median normalisation. (B) Selection of miRNAs differentially expressed in seven paired normal-NPC tissues. Differentially expressed miRNAs were selected based on $t$-test $(P<0.0 \mathrm{I})$ and median fold change $(\geqslant 3$-fold). (C) Principle component analysis using the expression levels of 35 miRNAs in 9 normal (blue) and I 3 NPC (red) samples. (D) Unsupervised hierarchical clustering of 35 differentially expressed miRNAs in normal (blue) and NPC (red) samples. The hierarchical clustering was performed using Pearson's dissimilarity as distance measure and Ward's method for linkage analysis. MicroRNA levels were expressed after standardisation.

miRNA expression pattern observed in our study is similar to earlier reports on other human cancers (Lu et al, 2005; Muralidhar et al, 2007).

\section{In silico analysis of pathways specifically targeted by down-modulated miRNAs}

The profiling analysis indicated that a large number of miRNAs are down-modulated in NPC tissues. As miRNAs are negative regulators of protein-coding genes, down-modulation of these miRNAs are expected to cause an upregulation of their target genes and alterations of the associated cellular pathways in NPC tissues. To estimate the overall effect of these down-modulated miRNAs on cellular functions, we adopted a two-stage approach as depicted in Figure $3 \mathrm{~A}$. The first stage was designed to identify target genes coregulated by these down-modulated miRNAs. The second stage performed a pathway enrichment analysis using the coregulated targets to identify cellular functions specifically regulated by these down-modulated miRNAs.

Most computational algorithms predict miRNA targets on the basis of sequence complementarity and/or thermostability (Lewis et al, 2003; John et al, 2004). However, recent studies indicated that many additional factors, such as local AU content and site position, can significantly affect the target site efficacy (Grimson et al, 2007). The overall target efficacy can be expressed by a context score. The correlation between context score and site efficacy has been validated in both mRNA and protein levels (Baek et al, 2008). Therefore, the concept of context score was implemented to select high confidence targets for the downmodulated miRNAs. The context score threshold for high efficacy target was set at -0.2 .

To identify coregulated targets for the down-modulated miRNAs, we retrieved all target genes listed in the TargetScan database (http://www.targetscan.org/; Lewis et al, 2003), which includes targets for 456 miRNA families predicted by seed sequence complementarity. Low confidence targets were eliminated by filtering out targets with total context score greater than -0.2 . Two miRNAs, miR-34c-3p, and miR-30a* were not present in the TargetScan database, and therefore were excluded from further analysis. The 22 down-modulated miRNAs ('down-miR') were used for target prediction and pathway analysis. To enhance the specificity of the target and pathway analysis, a control set of 22 miRNAs ('ctrl-miR') was included in the target prediction and pathway analysis. These 22 miRNAs showed constant expression level in normal and NPC tissues and shared no sequence homology in their seed regions with the 22 down-modulated miRNAs. The seed sequence and the number of unique target predicted for individual miRNA were listed in Table 2.

The number of total targets predicted for down-miR and ctrl-miR was 8014 and 8039, respectively. Distribution of predicted targets $v s$ coregulating miRNAs for down-miR and ctrl-miR was shown in Figure 3B. Within each target group, approximately half 
Table I MicroRNAs significantly altered in NPC tissues

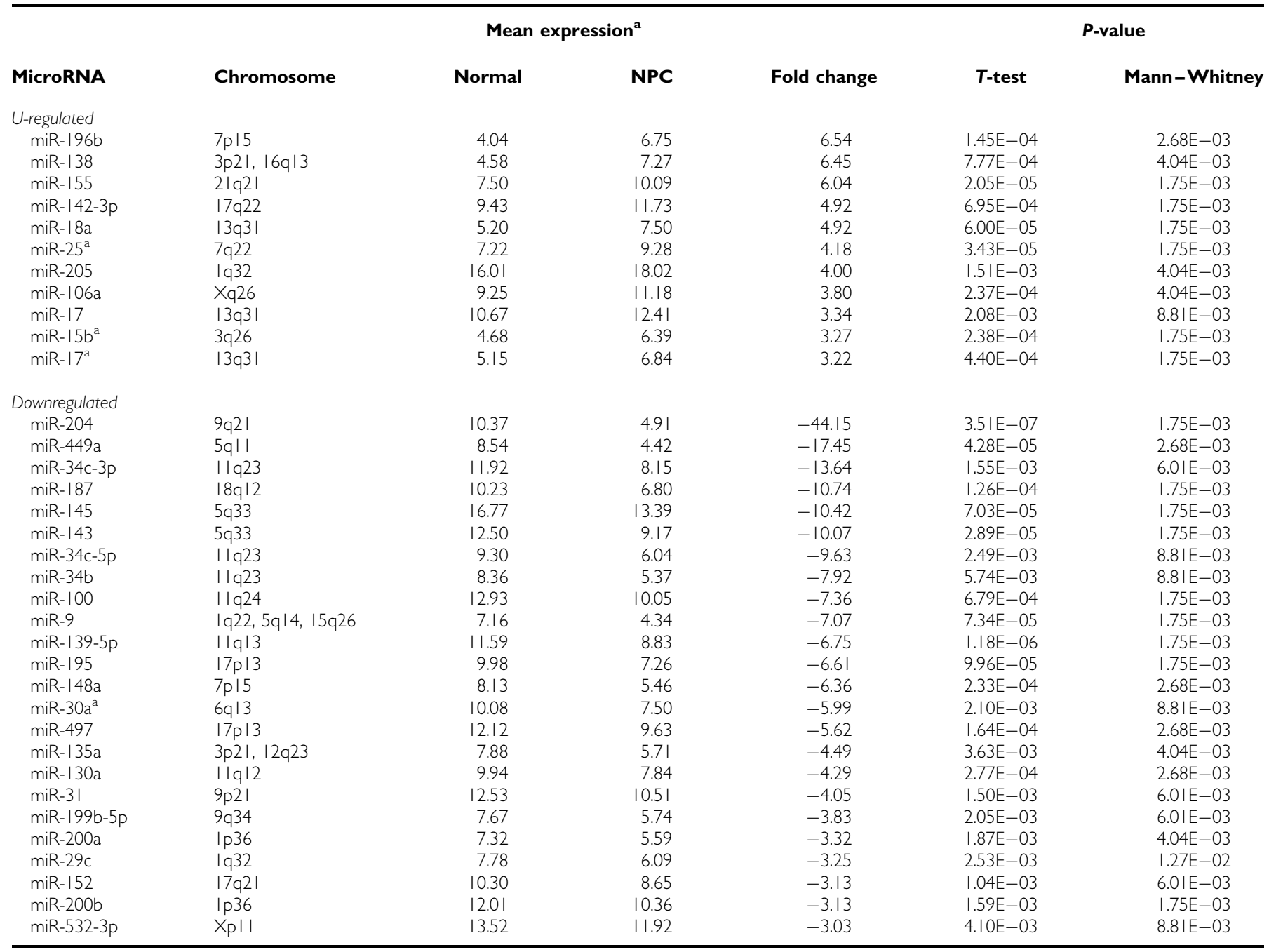

Mean expression levels expressed as $39-C_{\mathrm{t}}$.
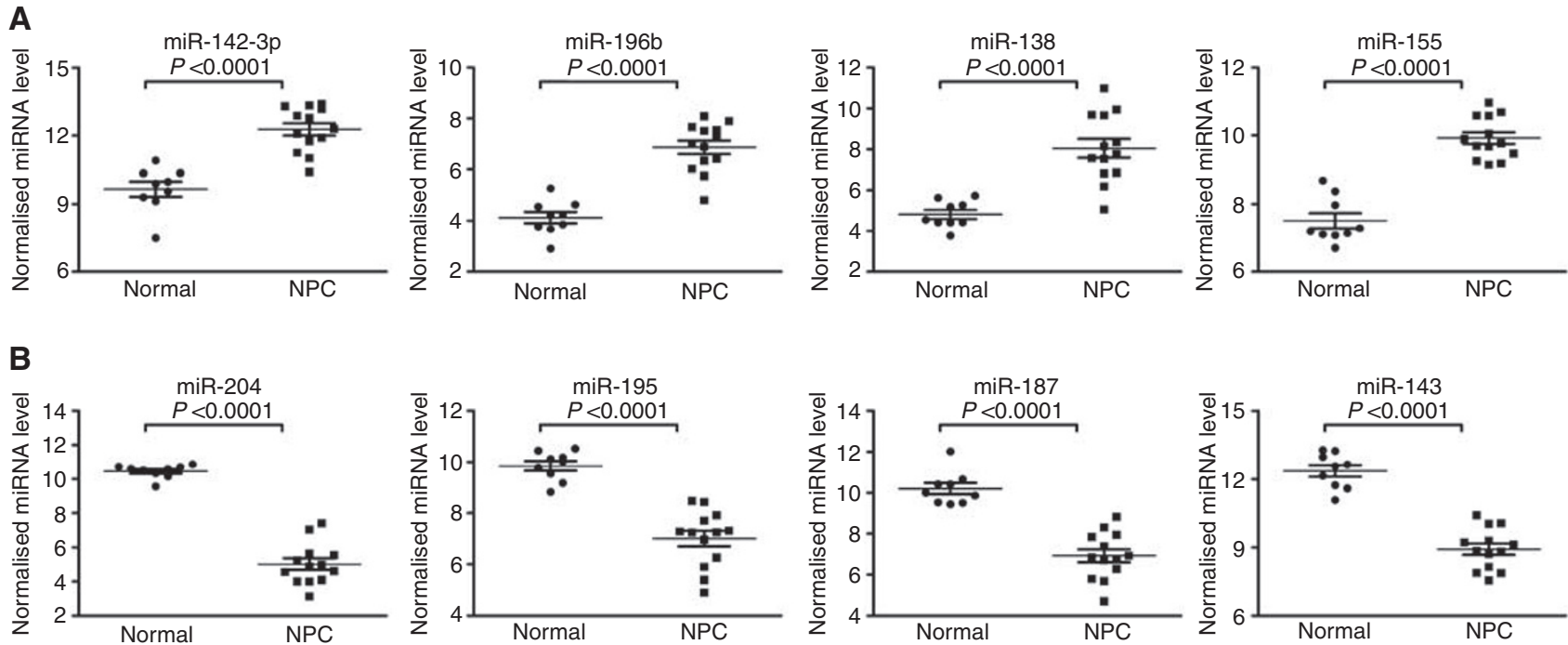

Figure 2 Significantly modulated MicroRNAs (miRNAs) in 9 normal and I 3 NPC tissues. (A) Expression levels of four miRNAs significantly upregulated in NPC tissues. (B) Expression levels of four miRNAs significantly downregulated in NPC tissues. Expression levels of miRNAs were expressed as $39-C_{t}$ after normalisation. P-value for each miRNA was calculated using two-tailed $t$-test. 
A

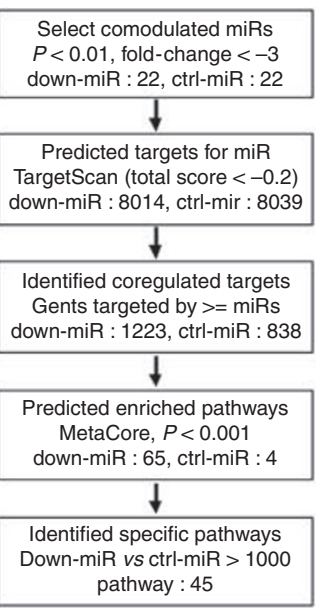

B

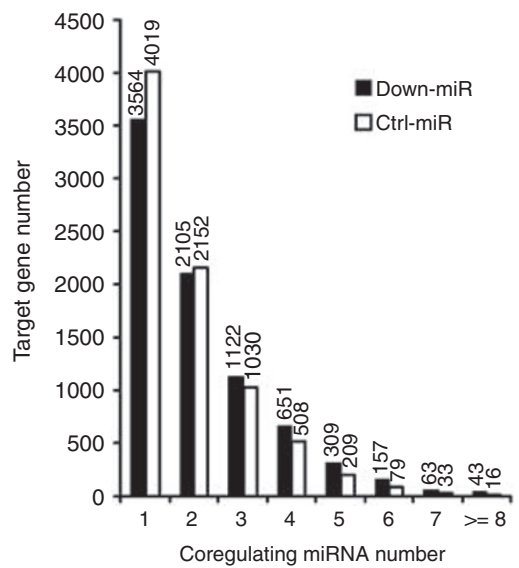

C

Coregulating $\mathrm{miR} \geq 4$
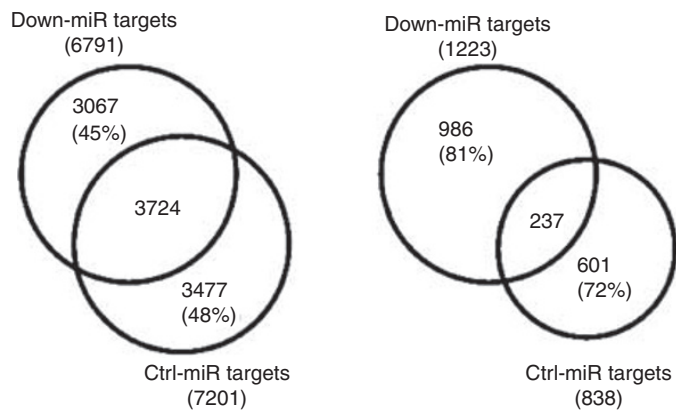

D

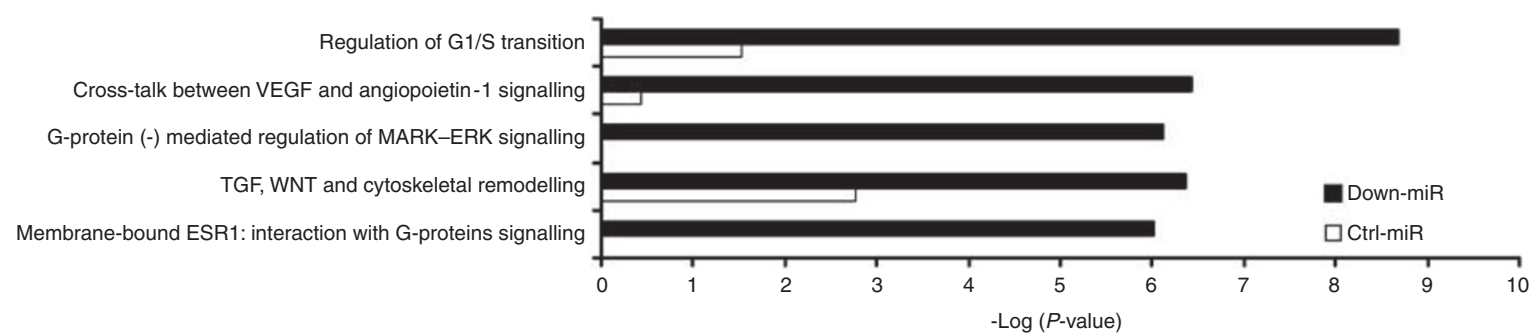

Figure 3 Analysis of collective regulated pathways. (A) Flow diagram depicting the process to identify the coregulated targets and specifically enriched pathways. (B) Distribution of predicted targets regulated by down-miR and ctrl-miR. (C) Distribution of cumulative target number coregulated by multiple microRNAs. (D) Pathways significantly and specifically enriched by down-miR targets.

Table 2 MicroRNAs selected for taget analysis

\begin{tabular}{llrllr}
\hline & $\begin{array}{l}\text { Seed } \\
\text { sequence }\end{array}$ & Target $^{\mathbf{a}}$ & & $\begin{array}{l}\text { Seed } \\
\text { sequence }\end{array}$ & Target $^{\mathbf{a}}$ \\
\hline Down-miR & & & Ctrl-miR & & \\
miR-100 & ACCCGUA & 44 & miR-101 & ACAGUAC & 1063 \\
miR-130a & AGUGCAA & 865 & miR-103 & GCAGCAU & 759 \\
miR-135a & AUGGCUU & 757 & miR-129-3p & AGCCCUU & 480 \\
miR-139-5p & CUACAGU & 650 & miR-140-3p & ACCACAG & 857 \\
miR-143 & GAGAUGA & 736 & miR-146a & GAGAACU & 640 \\
miR-145 & UCCAGUU & 956 & miR-146b-5p & GAGAACU & 642 \\
miR-148a & CAGUGCA & 808 & miR-186 & AAAGAAU & 2030 \\
miR-152 & CAGUGCA & 798 & miR-193a-3p & ACUGGCC & 423 \\
miR-187 & CGUGUCU & 85 & miR-193b & ACUGGCC & 422 \\
miR-195 & AGCAGCA & 1078 & miR-194 & GUAACAG & 780 \\
miR-199b-5p & CCAGUGU & 637 & miR-24 & GGCUCAG & 768 \\
miR-200a & AACACUG & 1255 & miR-27b & UCACAGU & 1162 \\
miR-200b & AAUACUG & 1393 & miR-299-5p & GGUUUAC & 511 \\
miR-204 & UCCCUUU & 1158 & miR-320 & AAAGCUG & 1017 \\
miR-29c & AGCACCA & 722 & miR-324-5p & GCAUCCC & 341 \\
miR-31 & GGCAAGA & 647 & miR-362-5p & AUCCUUG & 493 \\
miR-34b & AAUCACU & 618 & miR-365 & AAUGCCC & 560 \\
miR-34c-5p & GGCAGUG & 703 & miR-483-3p & CACUCCU & 458 \\
miR-449a & GGCAGUG & 716 & miR-500 & AAUCCUU & 354 \\
miR-497 & AGCAGCA & 994 & miR-516a-5p & UCUCGAG & 622 \\
miR-532-5p & AUGCCUU & 597 & miR-550 & GUGCCUG & 417 \\
miR-9 & CUUUGGU & 824 & miR-654-3p & AUGUCUG & 494 \\
\hline
\end{tabular}

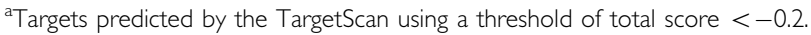

of the predicted targets were recognised by single miRNA ( $44 \%$ of down-miR targets and $50 \%$ of the ctrl-miR targets). A majority of targets were recognised by three or fewer miRNAs $(85 \%$ of down-
miR targets and $90 \%$ of ctrl-miR targets). Between the two target groups, more than $55 \%$ of predicted targets were shared by both groups when the number of coregulating miRNA was equal or less than three. However, when the number of coregulating miRNA was equal or more than four, the fraction of overlapping targets decreased to less than $20 \%$. These results suggested that genes coregulated by four or more miRNAs provided a better distinction between the two target groups and were more suitable for pathway-enrichment analysis.

The number of targets regulated by four or more miRNAs was 1223 and 838 for down-miR and ctrl-miR, respectively. These two target groups were selected and uploaded into MetaCore for pathway enrichment analysis. Statistically enriched pathways were identified using a threshold $P$-value of 0.001 . Sixty-five pathways were found to be statistically enriched with the down-miR targets, whereas only four pathways were enriched with the ctrl-miR targets. For each pathway, we calculated the ratio of $P$-values between down-miR and ctrl-miR to determine the specificity. With a $P$-value ratio $>1000$ as the criteria, we identified 45 pathways specifically enriched by down-miR targets. These specifically targeted pathways include many pathways involved in tumour pathogenesis, such as TGF-Wnt pathways, G1-S cell cycle progression, VEGF signalling pathway, apoptosis and survival pathways, and IP3 signalling pathways. The five most specifically targeted pathways were shown in Figure 3D. Table 3 listed the specifically targeted pathways grouped by their cellular functions.

\section{Validation of genes specifically targeted by the downregulated miRNAs}

Regulation of G1/S transition and cross-talk between VEGF and angiopoietin-1 signalling are the two most significantly pathways 
Table 3 Specifically targeted pathways

\begin{tabular}{|c|c|c|c|c|c|c|c|}
\hline \multirow[b]{2}{*}{ Category } & \multirow[b]{2}{*}{ Pathway } & \multicolumn{3}{|c|}{ Gene number } & \multicolumn{3}{|c|}{$P$-value } \\
\hline & & Total $^{\mathbf{a}}$ & Down-miR & Ctrl-miR & Down-miR & Ctrl-miR & Ratio \\
\hline \multirow{3}{*}{ Cytoskeleton remodelling } & Cytoskeleton remodelling & 87 & 15 & 6 & $2.72 \mathrm{E}-07$ & $2.16 \mathrm{E}-03$ & $7.93 E+03$ \\
\hline & $\mathrm{ACM} 3$ and $\mathrm{ACM} 4$ in keratinocyte migration & 37 & 7 & 0 & $2.51 \mathrm{E}-04$ & $1.00 \mathrm{E}+00$ & $3.99 \mathrm{E}+03$ \\
\hline & Role of PKA in cytoskeleton reorganisation & 39 & 8 & 2 & $4.90 \mathrm{E}-05$ & $1.21 \mathrm{E}-0 \mid$ & $2.47 E+03$ \\
\hline Cell cycle & Regulation of GI/S transition & 40 & 10 & 3 & $7.90 \mathrm{E}-07$ & $2.33 \mathrm{E}-02$ & $2.95 E+04$ \\
\hline \multirow{10}{*}{ Development } & IGF-RI signalling & 43 & 10 & । & $1.63 \mathrm{E}-06$ & $4.88 \mathrm{E}-01$ & $3.00 E+05$ \\
\hline & Ligand-independent activation of ESRI and ESR2 & 44 & 10 & i & $2.04 \mathrm{E}-06$ & $4.96 \mathrm{E}-01$ & $2.43 \mathrm{E}+05$ \\
\hline & G-protein-mediated regulation of MARK-ERK signalling & 44 & 9 & 0 & $1.68 \mathrm{E}-05$ & $1.00 \mathrm{E}+00$ & $5.94 \mathrm{E}+04$ \\
\hline & A3 receptor signalling & 47 & 9 & 0 & $2.95 \mathrm{E}-05$ & $1.00 E+00$ & $3.39 E+04$ \\
\hline & $\beta$-Adrenergic receptor signalling through cAMP & 52 & 9 & 0 & $6.84 \mathrm{E}-05$ & $1.00 E+00$ & $1.46 \mathrm{E}+04$ \\
\hline & Membrane-bound ESRI: interaction with growth facto & 38 & 8 & । & $4.02 \mathrm{E}-05$ & 4.47E-01 & $1.11 E+04$ \\
\hline & Dopamine D2 receptor transactivation of EGFR & 24 & 6 & 0 & $1.39 \mathrm{E}-04$ & $1.00 \mathrm{E}+00$ & $7.22 E+03$ \\
\hline & $\delta$-Type opioid receptor-mediated cardioprotecti & 37 & 7 & i & $2.5 \mathrm{IE}-04$ & $4.38 \mathrm{E}-01$ & $1.75 E+03$ \\
\hline & ERBB family signalling & 38 & 7 & 1 & $2.98 \mathrm{E}-04$ & 4.47E-0I & $1.50 \mathrm{E}+03$ \\
\hline & GDNF family signalling & 44 & 7 & 0 & 7.57E-04 & $1.00 \mathrm{E}+00$ & $1.32 E+03$ \\
\hline \multirow{6}{*}{ Signal transduction } & AKT signalling & 40 & 9 & 1 & $7.34 \mathrm{E}-06$ & 4.64E-0I & $6.32 E+04$ \\
\hline & Calcium signalling & 43 & 9 & 2 & $1.38 \mathrm{E}-05$ & $1.42 \mathrm{E}-0 \mid$ & $1.03 E+04$ \\
\hline & ERK interactions: inhibition of ERK & 35 & 8 & 2 & $2.12 \mathrm{E}-05$ & $1.01 \mathrm{E}-0 \mid$ & $4.77 \mathrm{E}+03$ \\
\hline & IP3 signalling & 49 & 9 & 2 & $4.19 E-05$ & $1.74 \mathrm{E}-0 \mid$ & $4.16 E+03$ \\
\hline & cAMP signalling & 36 & 8 & 2 & $2.64 \mathrm{E}-05$ & $1.06 \mathrm{E}-0 \mid$ & $4.01 E+03$ \\
\hline & PTEN pathway & 45 & 7 & 0 & $8.71 E-04$ & $1.00 E+00$ & $1.15 E+03$ \\
\hline Apoptosis and survival & BAD phosphorylation & 41 & 8 & । & $7.17 \mathrm{E}-05$ & $4.72 \mathrm{E}-01$ & $6.59 E+03$ \\
\hline \multirow[t]{3}{*}{ Transcription } & ChREBP regulation pathway & 22 & 6 & 0 & $8.15 E-05$ & $1.00 \mathrm{E}+00$ & $1.23 E+04$ \\
\hline & CREB pathway & 42 & 9 & 2 & $1.13 E-05$ & |.37E-0| & $1.21 E+04$ \\
\hline & Androgen receptor nuclear signalling & 45 & 7 & 0 & 8.7IE-04 & $1.00 \mathrm{E}+00$ & $1.15 E+03$ \\
\hline
\end{tabular}

${ }^{a}$ Total gene number in the pathway.

Table 4 Targets selected for validation

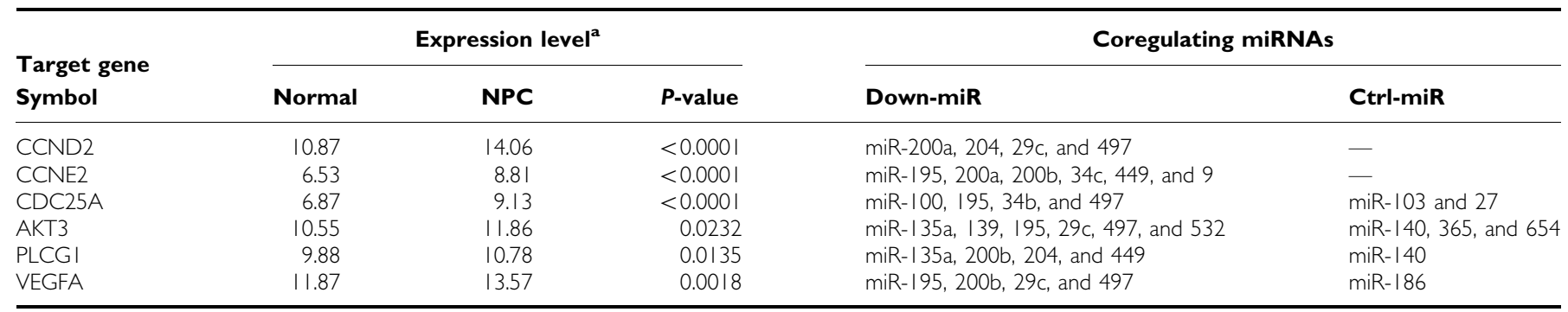

Expression levels expressed as $39-C_{\mathrm{t}}$ values after normalisation with $\beta$-2-microglobulin, actin, and GAPDH.

targeted by down-miR. To validate the effect of down-miR on these two pathways in NPC, we selected three predicted target genes from each pathway and compared their expression levels in normal and NPC samples (Table 4). Real-time RT-PCR analysis revealed that the expression levels of all six predicted targets, including cyclin D2 (CCND2), cyclin E2 (CCNE2), CDC25A, VEGFA, phospholipase C- $\gamma 1$ (PLCG1), and AKT3, were significantly elevated in NPC tissues (Figure 4A and B). We also examined the protein levels of CCNE2 in NPC tissue sections by immunohistochemical staining to identify which cell type in the tumour mass express cyclin E2 protein. Two representative cases of cyclin E2 staining are shown in Figure 4C. Strong positive cyclin E2 staining was detected in tumour cells (left panels), but not in paired normal nasopharyngeal epithelium (right panels). This result confirmed that the predicted targets of down-miR are upregulated in NPC. 
A

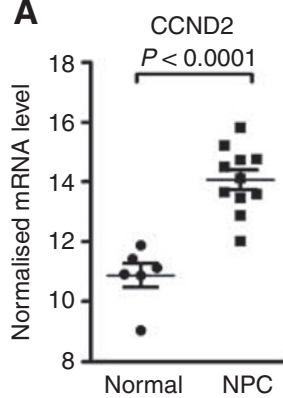

B

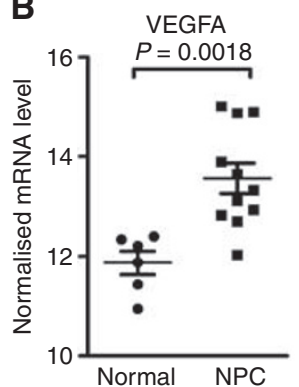

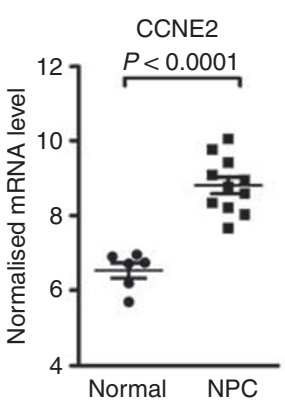
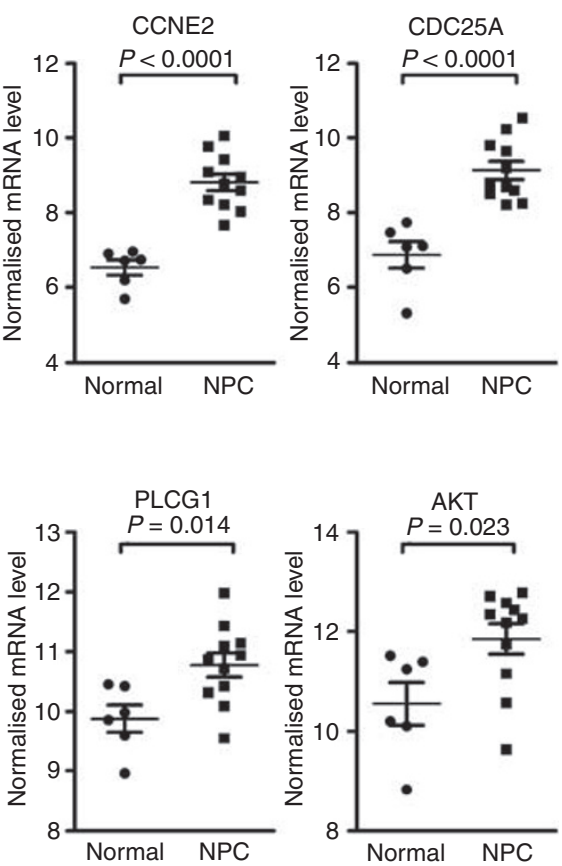

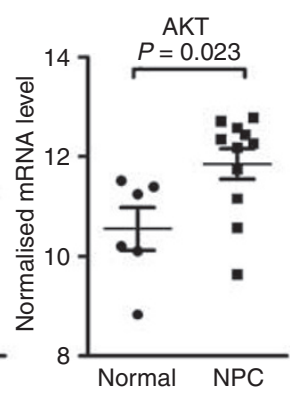

C NPC
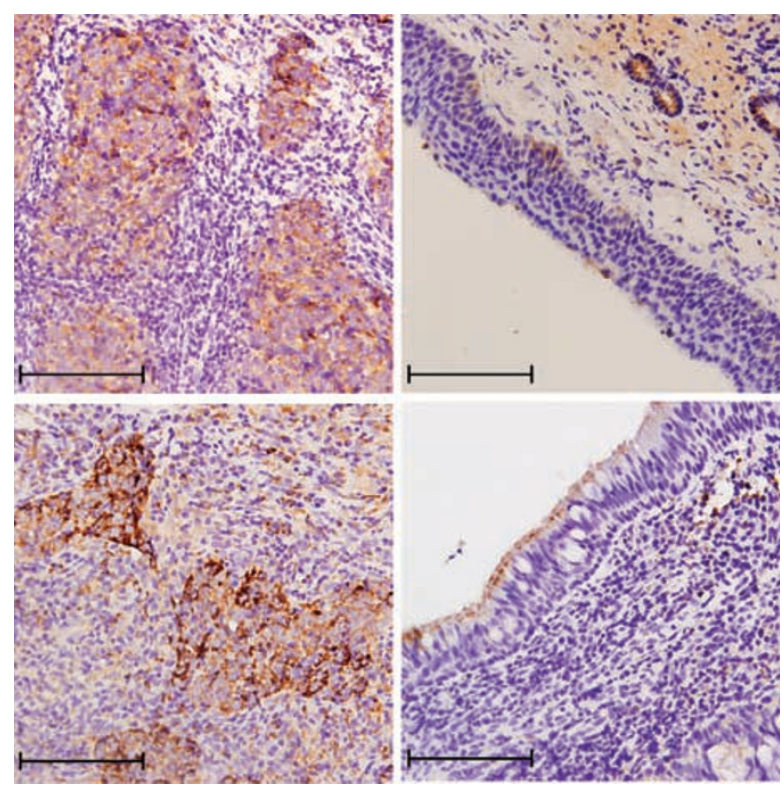

Figure 4 The upregulation of microRNA (miRNA) coregulated targets in NPC. (A) Quantification of coregulated targets in growth factor-regulated GI-S cell cycle pathway: cyclin D2 (CCND2), cyclin E2 (CCNE2), and CDC25A. (B) Quantification of coregulated targets involved in VEGF pathway: VEGFA, PLCGI (phospholipase $C-\gamma \mid$ ), and AKT. Expression level of each gene is expressed as $39-C_{t}$ after normalised to three internal controls. (C) Specimens of NPC tissues were stained with the anti-CCNE2 antibody. Shown here are two representative cases containing tumour cells with positive CCNE2 staining (left panels), as well as non-tumour epithelial cells with negative CCNE2 staining (right panels). Original magnification: $\times 400$; Bar, I00 $\mu$ m.

The 3'UTR of cyclin E2 contains binding sites for many different miRNAs. Six of them (miR-34c-5p, miR-449, miR-200a, miR-200b, miR-195, and miR-9) were down-modulated in NPC (Figure 5A and $\mathrm{B}$ ). We further analysed the expression correlation between three of the down-modulated miRNAs and cyclin E2 in 16 samples, including $10 \mathrm{NPC}$ and 6 normal nasopharyngeal tissues. Expression of all three miRNAs showed significant inverse correlation (Pearson's correlation coefficient $<-0.5, P<0.05$ ) with the expression level of cyclin E2 (Figure $5 \mathrm{C}$ ). These results indicated that the down-modulated miRNAs cooperatively upregulated critical targets in the G1/S transition pathway. To determine whether the expression level of CCNE2 is indeed regulated by down-modulated miRNAs, we examined the mRNA and protein level of CCNE2 in HK1 cells overexpressing one of the coregulating miRNA, miR-9 (Figure 5D). As shown in Figure 5E and F, HK1/ miR-9 cells showed a significant decrease in CCNE2 mRNA and protein levels, indicating that CCNE2 is a direct target of miR-9.

\section{DISCUSSION}

This study used a stem-loop RT-PCR method to quantify the expression levels of 270 miRNAs in NPC tissues. Using a three-fold change as the cutoff, we identified 35 miRNAs whose expression levels were significantly altered in NPC tissues. Unsupervised hierarchical clustering using these differentially expressed miRNAs clearly segregated NPC tissues from the normal samples. Among the differentially expressed miRNAs identified in this study, many are known oncogenic or tumour-suppressive miRNAs previously shown to be dysregulated in other cancer types (Chen, 2005; Croce, 2008). Our results provided further support for using miRNA expression patterns as diagnostic markers.

The profiling analysis identified a group of miRNAs whose expression was significantly down-modulated in NPC. To assess the global impact of these down-modulated miRNAs, we conducted a high stringency target prediction to identify potential target genes, which were coregulated by multiple down-modulated miRNAs, and then analysed the cellular pathways, which were specifically enriched with these coregulated genes. Results from the pathway enrichment analysis suggested that these down-modulated miRNAs selectively target signalling cascades involved in cell cycle regulation, cell survival and apoptosis, and cytoskeleton remodelling. Quantification of target genes in clinical samples confirmed the elevated expression of several coregulated targets, and revealed a significant inverse correlation between the downmodulated miRNAs and their targets. These results indicated that the target prediction combined with pathway enrichment analysis is an effective approach in investigating the influence of multiple miRNAs.

Recently, Sengupta et al (2008) identified eight miRNAs differentially expressed in NPC. Three of the most significantly altered miRNAs, including miR-29c, miR-34b, and miR-34c, also showed significantly reduced expression in our NPC samples. However, the remaining five miRNAs identified in their study did not show significant alteration in the current study. The discrepancy could be due to the difference in sample preparation or difference between microarray and RT-PCR assay.

Expression of many oncogenic miRNAs, including miR-155, miR-106a, and three miRNAs from the miR-17-92 cluster, were found significantly elevated in NPC. The miR-155 upregulates the $\mathrm{NF}-\kappa \mathrm{B}$ signalling pathway and is highly expressed in many haematological malignancies and solid tumours (Rai et al, 2008). MicroRNAs from the miR-17-92 cluster suppress multiple proliferation inhibitors as well as proapoptotic targets, and promote tumour formation (Matsubara et al, 2007; Cloonan et al, 2008). The upregulation of the miR-17-92 cluster is noted in leukaemia, thyroid cancer, and lung cancer (Hayashita et al, 2005; Venturini et al, 2007; Takakura et al, 2008).

The down-modulated mRNAs include miR-34b/miR-34c cluster, the miR-143/miR-145 cluster, and the miR-195/miR-497 cluster. 
A

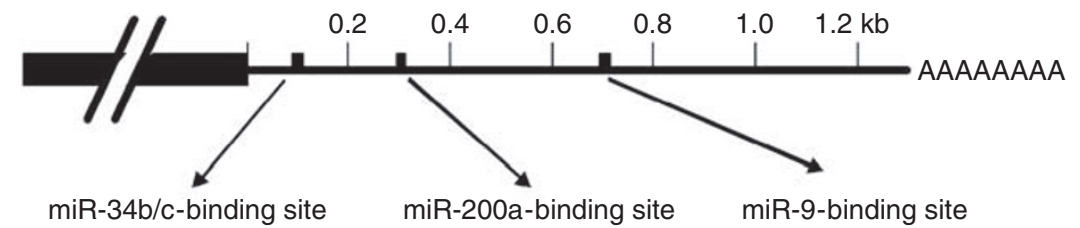

5' CCAAUUCACAAGUUACACUgCCA UUUCCUUUAAUC -- CAgUgUUA CUAAACAGUGgGaguaCCAAAGA

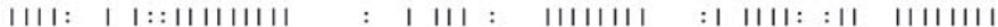
3 ' CGUUAGUCGAUUGAUGUGACGGA UGUAGCAAUGGUCUGUCACAAU AGUAUGUCGAUCUAUUGGUUUCU
D

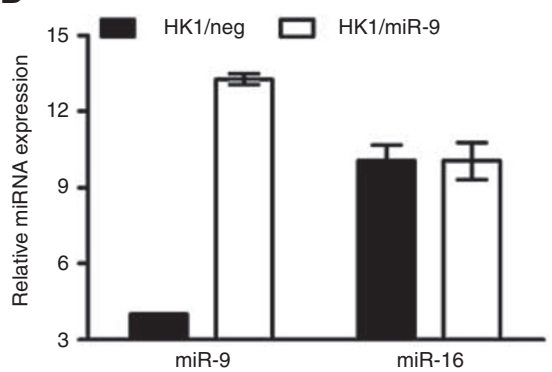

$\mathbf{E}$
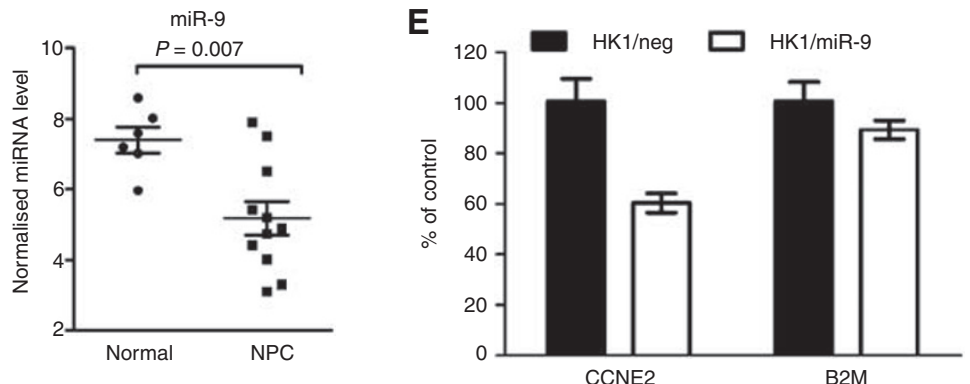

$\mathbf{F}$

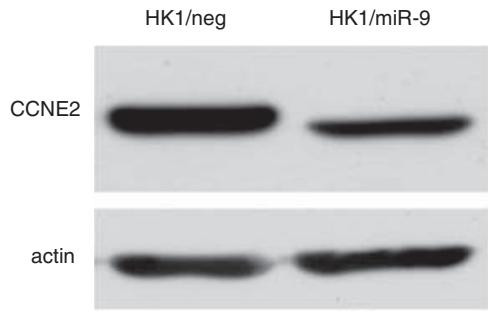

Figure 5 Inverse correlation between cyclin E2 expression with miR-34c, miR-200a, and miR-9 in NPC. (A) Predicted binding sites for miR-34c-5p, miR-200a, and miR-9 on the 3'UTR of cyclin E2. (B) Expression levels of miR-34c-5p, miR-200a, and miR-9 in normal and NPC tissues. (C) Correlation analysis between cyclin E2 and three microRNAs. Pearson's correlation coefficient and P-value for individual analysis are shown in the inserts. (D) Quantification of miR-9 in HKI cells after transduction with either negative control lentivirus (HKI/neg) or lentivirus encoding miR-9 (HKI/miR-9). Levels of miR-9 and miR-16 were expressed as $39-C_{+}$. (E) Quantification of CCNE2 and $\beta$-2-microglobulin (B2M) transcripts in HKI/neg and HKI/miR-9 cells. Results are mean \pm s.d. of three independent experiments. A significant reduction in CCNE2 level was observed after miR-9 expression (HKI/neg vs HKI/miR-9, CCNE2: $P=0.014, B 2 M: P=0.258$ ). (F) Reduced expression of CCNE2 protein in HKI/miR-9 cells.

Both miR-34b and miR-34c are downstream components of the p53 tumour suppressor network (Corney et al, 2007; Tarasov et al, 2007). Induction of miR-34b and miR-34c leads to apoptosis or cellular senescence, whereas reduced miR-34b/c expression attenuates p53-mediated cell death (Tarasov et al, 2007; Welch et al, 2007). Reduced expression of miR-143 and miR-145 has been documented in cervical cancer, colon cancer, and B-cell malignancies (Michael et al, 2003; Akao et al, 2007; Wang et al, 2008). Forced expression of miR-143 and miR-145 inhibit cell growth in cervical cancer cells (Wang et al, 2008). Although the biological function of miR-195 and miR-497 has not been characterised, reduced expression of miR-195 and miR-497 on the $17 \mathrm{p} 13$ locus has been documented in primary peritoneal carcinoma (Flavin et al, 2008).

In addition to the commonly observed miRNAs, this study also identified several dysregulated miRNAs whose aberrant expression has not been reported before. For example, miR-25* was significantly elevated in NPC and miR-532, and miR-199b-5p were down-modulated. MiR-449 shared the same seed sequence with miR-34c and was found down-modulated in our study. Similarly, miR-152 shared the same seed sequence with miR-148a, and both miRNAs were down-modulated in NPC.
Recently, two studies using microarray and proteomic approach clearly showed that a single miRNA can regulate the expression of hundreds of target genes (Baek et al, 2008; Selbach et al, 2008). The widespread repression can be detected in both mRNA and protein levels, but the degree of repression for individual target gene is usually very mild. On the other hand, miRNA profiling analysis typically uncovered aberrant expression of multiple miRNAs in the diseased tissues ( $\mathrm{Lu}$ et al, 2005). How to assess the biological consequence of miRNA dysregulation has become a major challenge. To overcome this difficulty, Gusev et al (2007) used a computational approach to calculate the global pattern of cellular functions and pathways affected by the coexpressed miRNAs.

In this study, we adopted the systems biology-based approach to investigate the global impact of differentially expressed miRNAs in the pathogenesis of NPC. Similar to the strategy described by Gusev et al (2007), we analysed the major signalling pathways that are most likely to be affected by the coexpressed miRNAs. Two modifications were introduced to enhance our confidence in target prediction and pathway analysis.

To enhance the accuracy for miRNA target prediction, we implemented the 'context score' concept during the target prediction process. Only genes with a total context score less than -0.2 were 
included in our target pool. The concept of context score was first proposed by Grimson et al (2007) to evaluate the site efficacy of miRNA target using microarray data. The 'context score' combined the complementarity of seed sequence, local AU content, site position, and additional base pairing at the $3^{\prime}$ site of miRNA to evaluate the site efficacy between miRNAs and their targets. This concept was further supported by the data from recent proteomic studies (Baek et al, 2008).

To enhance the specificity of pathway enrichment analysis, we selected a set of control miRNAs, which were not altered in NPC, and conducted the target prediction and pathway enrichment analysis in parallel. The probability of a gene targeted by multiple miRNAs increases as the length of its $3^{\prime}$ UTR increases. This potential bias introduced by genes with longer $3^{\prime}$ UTR can be minimised by comparing it with the targets coregulated by the control miRNAs. The pathway specificity was calculated by comparing the $P$-values between these two target sets. This strategy effectively addressed the complexity that arise from the coexpressed miRNAs and coregulated targets.

Our studies revealed that the targets coregulated by the downmodulated miRNA are specifically enriched with genes involved in 'TGF-WNT and cytoskeletal remodelling' pathways. Predicted targets include several key regulators of the Wnt pathway, such as WNT1, WNT2, frizzled homologue 3, 7, and 8, AKT, and NF- $\kappa \mathrm{B} 1$, as well as multiple extracellular matrix proteins, such as collagen 4A1, 4A4, and fibronectin 1 . Studies by Zeng et al (2007), using profiling and immunohistochemical stains, shows that the protein levels of these coregulated targets were significantly elevated in NPC tissues, whereas elevated expression of extracellular matrix proteins was shown by Sengupta et al (2008) using Q-PCR. The analysis is consistent with the observation that WNT signalling pathway is abnormally regulated in NPC (Shi et al, 2006; Zeng et al, 2007; Chou et al, 2008).

Another pathway preferentially targeted by the down-modulated miRNAs involved growth factor-regulated G1-S cell cycle progression. Several cell cycle regulators, including cyclin D2, cyclin E2, and $\mathrm{CDC} 25 \mathrm{~A}$ are coregulated by the downregulated miRNAs. Reverse transcriptase PCR analysis confirmed the elevated expression of these target genes in NPC tissues. Correlation analysis further revealed a significant inverse correlation between the level of cyclin E2 and three of its cognate miRNAs, miR-34c, miR-200a, and miR-9. These results suggest that the aberrant cell cycle control in NPC tissues may be tightly linked to the dysregulated expression of miRNAs (Hwang et al, 2002; Tao et al, 2005; Chou et al, 2008).

The third signalling pathway, significantly targeted by downmodulated miRNAs, is the VEGF-regulated angiogenesis. Predicted targets include VEGF-A, PLC- $\gamma$, and AKT. Earlier studies have shown that VEGF is widely expressed in NPC tissues, and elevated VEGF expression is associated with local recurrence and distal metastasis (Li et al, 2008; Pan et al, 2008). Current studies revealed that several key regulators on the VEGF-regulated signalling pathway are cotargeted by multiple miRNAs, including miR-135a, miR29c, miR195 , and miR-497. Simultaneous down-modulation of these miRNAs may be responsible for the elevated VEGF signalling in NPC.

Recent studies using an miRNA target reverse screening method showed that miR-16 family triggers a cell cycle arrest by silencing multiple cell cycle regulatory genes simultaneously (Liu et al, 2008), rather than the individual target. Similarly, miR-17-5p regulates the cell cycle progression by coordinately suppressing more than 20 genes involved in the G1/S transition (Cloonan et al, 2008). It is evident that a better connection between cellular function and miRNA expression requires both computational as well as experimental approach. The context score filter and the use of control gene list significantly increased our confidence for target prediction and pathway analysis. Experimental validation and literature mining confirmed that the expression data detected in clinical samples are consistent with the computational prediction. This study has shown the systems biology approach as a valuable tool to uncover global functional change associated with miRNA dysregulation. Similar approach can be used to assist the functional interpretation of miRNA expression data in other human diseases.

\section{ACKNOWLEDGEMENTS}

We are extremely grateful to Dr Liang Ying and the Pathology Core at the Molecular Medicine Research Center for performing the immunohistochemisty and Mr Shih-Chi Yeh for performing the western blot. This study was supported by grants from the Ministry of Education to Chang Gung University.

Supplementary Information accompanies the paper on British Journal of Cancer website (http://www.nature.com/bjc)

\section{REFERENCES}

Akao Y, Nakagawa Y, Kitade Y, Kinoshita T, Naoe T (2007) Downregulation of microRNAs-143 and -145 in B-cell malignancies. Cancer Sci 98: $1914-1920$

Ambros V (2004) The functions of animal microRNAs. Nature 431: $350-355$

Asangani IA, Rasheed SA, Nikolova DA, Leupold JH, Colburn NH, Post S, Allgayer H (2008) MicroRNA-21 (miR-21) post-transcriptionally downregulates tumor suppressor Pdcd4 and stimulates invasion, intravasation and metastasis in colorectal cancer. Oncogene 27: 2128-2136

Baek D, Villen J, Shin C, Camargo FD, Gygi SP, Bartel DP (2008) The impact of microRNAs on protein output. Nature 455: $64-71$

Bartel DP (2004) MicroRNAs: genomics, biogenesis, mechanism, and function. Cell 116: $281-297$

Bushati N, Cohen SM (2007) microRNA functions. Annu Rev Cell Dev Biol 23: $175-205$

Calin GA, Sevignani C, Dumitru CD, Hyslop T, Noch E, Yendamuri S, Shimizu M, Rattan S, Bullrich F, Negrini M, Croce CM (2004) Human microRNA genes are frequently located at fragile sites and genomic regions involved in cancers. Proc Natl Acad Sci USA 101: 2999-3004

Chen C, Ridzon DA, Broomer AJ, Zhou Z, Lee DH, Nguyen JT, Barbisin M, Xu NL, Mahuvakar VR, Andersen MR, Lao KQ, Livak KJ, Guegler KJ
(2005) Real-time quantification of microRNAs by stem-loop RT-PCR. Nucleic Acids Res 33: e179

Chen CZ (2005) MicroRNAs as oncogenes and tumor suppressors. N Engl J Med 353: $1768-1771$

Chou J, Lin YC, Kim J, You L, Xu Z, He B, Jablons DM (2008) Nasopharyngeal carcinoma - review of the molecular mechanisms of tumorigenesis. Head \& Neck 30: 946-963

Cimmino A, Calin GA, Fabbri M, Iorio MV, Ferracin M, Shimizu M, Wojcik SE, Aqeilan RI, Zupo S, Dono M, Rassenti L, Alder H, Volinia S, Liu CG, Kipps TJ, Negrini M, Croce CM (2005) miR-15 and miR-16 induce apoptosis by targeting BCL2. Proc Natl Acad Sci USA 102: $13944-13949$

Cloonan N, Brown MK, Steptoe AL, Wani S, Chan WL, Forrest AR, Kolle G, Gabrielli B, Grimmond SM (2008) The miR-17-5p microRNA is a key regulator of the G1/S phase cell cycle transition. Genome Biol 9: R127

Corney DC, Flesken-Nikitin A, Godwin AK, Wang W, Nikitin AY (2007) MicroRNA-34b and MicroRNA-34c are targets of p53 and cooperate in control of cell proliferation and adhesion-independent growth. Cancer Res 67: $8433-8438$

Croce CM (2008) Oncogenes and cancer. N Engl J Med 358: 502-511

Croce CM, Calin GA (2005) miRNAs, cancer, and stem cell division. Cell 122: $6-7$ 
Flavin RJ, Smyth PC, Finn SP, Laios A, O’Toole SA, Barrett C, Ring M, Denning KM, Li J, Aherne ST, Aziz NA, Alhadi A, Sheppard BL, Loda M, Martin C, Sheils OM, O'Leary JJ (2008) Altered eIF6 and Dicer expression is associated with clinicopathological features in ovarian serous carcinoma patients. Mod Pathol 21: 676-684

Grimson A, Farh KK, Johnston WK, Garrett-Engele P, Lim LP, Bartel DP (2007) MicroRNA targeting specificity in mammals: determinants beyond seed pairing. Mol Cell 27: $91-105$

Gusev Y, Schmittgen TD, Lerner M, Postier R, Brackett D (2007) Computational analysis of biological functions and pathways collectively targeted by co-expressed microRNAs in cancer. BMC Bioinformatics 8(Suppl 7): S16

Hayashita Y, Osada H, Tatematsu Y, Yamada H, Yanagisawa K, Tomida S, Yatabe Y, Kawahara K, Sekido Y, Takahashi T (2005) A polycistronic microRNA cluster, miR-17-92, is overexpressed in human lung cancers and enhances cell proliferation. Cancer Res 65: 9628-9632

Hwang CF, Cho CL, Huang CC, Wang JS, Shih YL, Su CY, Chang HW (2002) Loss of cyclin D1 and p16 expression correlates with local recurrence in nasopharyngeal carcinoma following radiotherapy. Ann Oncol 13: $1246-1251$

John B, Enright AJ, Aravin A, Tuschl T, Sander C, Marks DS (2004) Human MicroRNA targets. PLoS Biol 2: e363

Kida Y, Han YP (2008) MicroRNA expression in colon adenocarcinoma. JAMA 299: 2628, author reply 2628-2629)

Lewis BP, Shih IH, Jones-Rhoades MW, Bartel DP, Burge CB (2003) Prediction of mammalian microRNA targets. Cell 115: 787-798

Li YH, Hu CF, Shao Q, Huang MY, Hou JH, Xie D, Zeng YX, Shao JY (2008) Elevated expressions of survivin and VEGF protein are strong independent predictors of survival in advanced nasopharyngeal carcinoma. J Transl Med 6: 1

Lim LP, Lau NC, Garrett-Engele P, Grimson A, Schelter JM, Castle J, Bartel DP, Linsley PS, Johnson JM (2005) Microarray analysis shows that some microRNAs downregulate large numbers of target mRNAs. Nature 433: $769-773$

Liu Q, Fu H, Sun F, Zhang H, Tie Y, Zhu J, Xing R, Sun Z, Zheng X (2008) miR-16 family induces cell cycle arrest by regulating multiple cell cycle genes. Nucleic Acids Res 36: 5391-5404

Lu J, Getz G, Miska EA, Alvarez-Saavedra E, Lamb J, Peck D, Sweet-Cordero A, Ebert BL, Mak RH, Ferrando AA, Downing JR, Jacks T, Horvitz HR, Golub TR (2005) MicroRNA expression profiles classify human cancers. Nature 435: $834-838$

Matsubara H, Takeuchi T, Nishikawa E, Yanagisawa K, Hayashita Y, Ebi H, Yamada H, Suzuki M, Nagino M, Nimura Y, Osada H, Takahashi T (2007) Apoptosis induction by antisense oligonucleotides against miR$17-5 \mathrm{p}$ and miR-20a in lung cancers overexpressing miR-17-92. Oncogene 26: $6099-6105$

Michael MZ, SM OC, van Holst Pellekaan NG, Young GP, James RJ (2003) Reduced accumulation of specific microRNAs in colorectal neoplasia. Mol Cancer Res 1: 882-891

Murakami Y, Yasuda T, Saigo K, Urashima T, Toyoda H, Okanoue T, Shimotohno K (2006) Comprehensive analysis of microRNA expression patterns in hepatocellular carcinoma and non-tumorous tissues. Oncogene 25: 2537-2545

Muralidhar B, Goldstein LD, Ng G, Winder DM, Palmer RD, Gooding EL, Barbosa-Morais NL, Mukherjee G, Thorne NP, Roberts I, Pett MR, Coleman N (2007) Global microRNA profiles in cervical squamous cell carcinoma depend on Drosha expression levels. J Pathol 212: 368-377

Pan J, Kong L, Lin S, Chen G, Chen Q, Lu JJ (2008) The clinical significance of coexpression of cyclooxygenases-2, vascular endothelial growth factors, and epidermal growth factor receptor in nasopharyngeal carcinoma. Laryngoscope 118: 1970-1975

Peltier HJ, Latham GJ (2008) Normalization of microRNA expression levels in quantitative RT-PCR assays: identification of suitable reference RNA targets in normal and cancerous human solid tissues. RNA 14: 844-852
Rai D, Karanti S, Jung I, Dahia PL, Aguiar RC (2008) Coordinated expression of microRNA-155 and predicted target genes in diffuse large B-cell lymphoma. Cancer Genet Cytogenets 181: 8-15

Raver-Shapira N, Marciano E, Meiri E, Spector Y, Rosenfeld N, Moskovits N, Bentwich Z, Oren M (2007) Transcriptional activation of miR-34a contributes to p53-mediated apoptosis. Mol Cell 26: 731-743

Schetter AJ, Leung SY, Sohn JJ, Zanetti KA, Bowman ED, Yanaihara N, Yuen ST, Chan TL, Kwong DL, Au GK, Liu CG, Calin GA, Croce CM, Harris CC (2008) MicroRNA expression profiles associated with prognosis and therapeutic outcome in colon adenocarcinoma. JAMA 299: $425-436$

Selbach M, Schwanhausser B, Thierfelder N, Fang Z, Khanin R, Rajewsky N (2008) Widespread changes in protein synthesis induced by microRNAs. Nature 455: 58-63

Sengupta S, den Boon JA, Chen IH, Newton MA, Stanhope SA, Cheng YJ, Chen CJ, Hildesheim A, Sugden B, Ahlquist P (2008) MicroRNA 29c is down-regulated in nasopharyngeal carcinomas, up-regulating mRNAs encoding extracellular matrix proteins. Proc Natl Acad Sci USA 105: $5874-5878$

Sevignani C, Calin GA, Nnadi SC, Shimizu M, Davuluri RV, Hyslop T, Demant P, Croce CM, Siracusa LD (2007) MicroRNA genes are frequently located near mouse cancer susceptibility loci. Proc Natl Acad Sci USA 104: $8017-8022$

Shi W, Bastianutto C, Li A, Perez-Ordonez B, Ng R, Chow KY, Zhang W, Jurisica I, Lo KW, Bayley A, Kim J, O'Sullivan B, Siu L, Chen E, Liu FF (2006) Multiple dysregulated pathways in nasopharyngeal carcinoma revealed by gene expression profiling. Int J Cancer 119: 2467-2475

Takakura S, Mitsutake N, Nakashima M, Namba H, Saenko VA, Rogounovitch TI, Nakazawa Y, Hayashi T, Ohtsuru A, Yamashita S (2008) Oncogenic role of miR-17-92 cluster in anaplastic thyroid cancer cells. Cancer Sci 99: 1147-1154

Tao Y, Song X, Deng X, Xie D, Lee LM, Liu Y, Li W, Li L, Deng L, Wu Q, Gong J, Cao Y (2005) Nuclear accumulation of epidermal growth factor receptor and acceleration of G1/S stage by Epstein-Barrencoded oncoprotein latent membrane protein 1. Exp Cell Res 303: $240-251$

Tarasov V, Jung P, Verdoodt B, Lodygin D, Epanchintsev A, Menssen A, Meister G, Hermeking H (2007) Differential regulation of microRNAs by p53 revealed by massively parallel sequencing: miR-34a is a p53 target that induces apoptosis and G1-arrest. Cell Cycle 6: 1586-1593

Venturini L, Battmer K, Castoldi M, Schultheis B, Hochhaus A, Muckenthaler MU, Ganser A, Eder M, Scherr M (2007) Expression of the miR-17-92 polycistron in chronic myeloid leukemia (CML) CD $34^{+}$ cells. Blood 109: 4399-4405

Wang X, Tang S, Le SY, Lu R, Rader JS, Meyers C, Zheng ZM (2008) Aberrant expression of oncogenic and tumor-suppressive microRNAs in cervical cancer is required for cancer cell growth. PLoS ONE 3: e2557

Welch C, Chen Y, Stallings RL (2007) MicroRNA-34a functions as a potential tumor suppressor by inducing apoptosis in neuroblastoma cells. Oncogene 26: 5017-5022

Yanaihara N, Caplen N, Bowman E, Seike M, Kumamoto K, Yi M, Stephens RM, Okamoto A, Yokota J, Tanaka T, Calin GA, Liu CG, Croce CM, Harris CC (2006) Unique microRNA molecular profiles in lung cancer diagnosis and prognosis. Cancer Cell 9: 189-198

Yu SL, Chen HY, Chang GC, Chen CY, Chen HW, Singh S, Cheng CL, Yu CJ, Lee YC, Chen HS, Su TJ, Chiang CC, Li HN, Hong QS, Su HY, Chen CC, Chen WJ, Liu CC, Chan WK, Chen WJ, Li KC, Chen JJ, Yang PC (2008) MicroRNA Signature Predicts Survival and Relapse in Lung Cancer. Cancer Cell 13: 48-57

Zeng ZY, Zhou YH, Zhang WL, Xiong W, Fan SQ, Li XL, Luo XM, Wu MH, Yang YX, Huang C, Cao L, Tang K, Qian J, Shen SR, Li GY (2007) Gene expression profiling of nasopharyngeal carcinoma reveals the abnormally regulated Wnt signaling pathway. Hum Pathol 38: $120-133$ 